\title{
Medical specialists break away from OMA at "worst possible time" warns Quebec specialist group
}

Cite as: CMAJ 2019 January 21;191:E85-6. doi: 10.1503/cmaj.109-5702

Posted on cmajnews.com on Dec. 18, 2018.

$\mathrm{T}$ he plan by several medical specialist groups to break away from the Ontario Medical Association (OMA) and negotiate directly with the provincial government may be the right move for specialists, but the timing - in the middle of arbitration proceedings for a new contract couldn't be worse, according to Dr. Diane Francoeur, president of the Fédération des médecins spécialistes du Québec (FMSQ).

"It is a good thing for them to separate like us, and we have offered help for the future. But to do it now during arbitration is the worst possible time," says Francoeur. She warns that the infighting will hand a huge advantage to the Ontario government during the arbitration hearings. "Divide and rule is a law that has been very successful in history no matter what the topic."

After eight specialist sections voted recently to break away from the OMA and form the Ontario Specialist Association (OSA), the Ontario government initially said it would pull out of the binding arbitration process that was supposed to come up with a new physician service agreement for Ontario's doctors, who have been without a contract since March 2014. The Ministry of Health and Long-Term Care said it didn't believe the OMA could deliver on the outcome of any arbitration agreement.

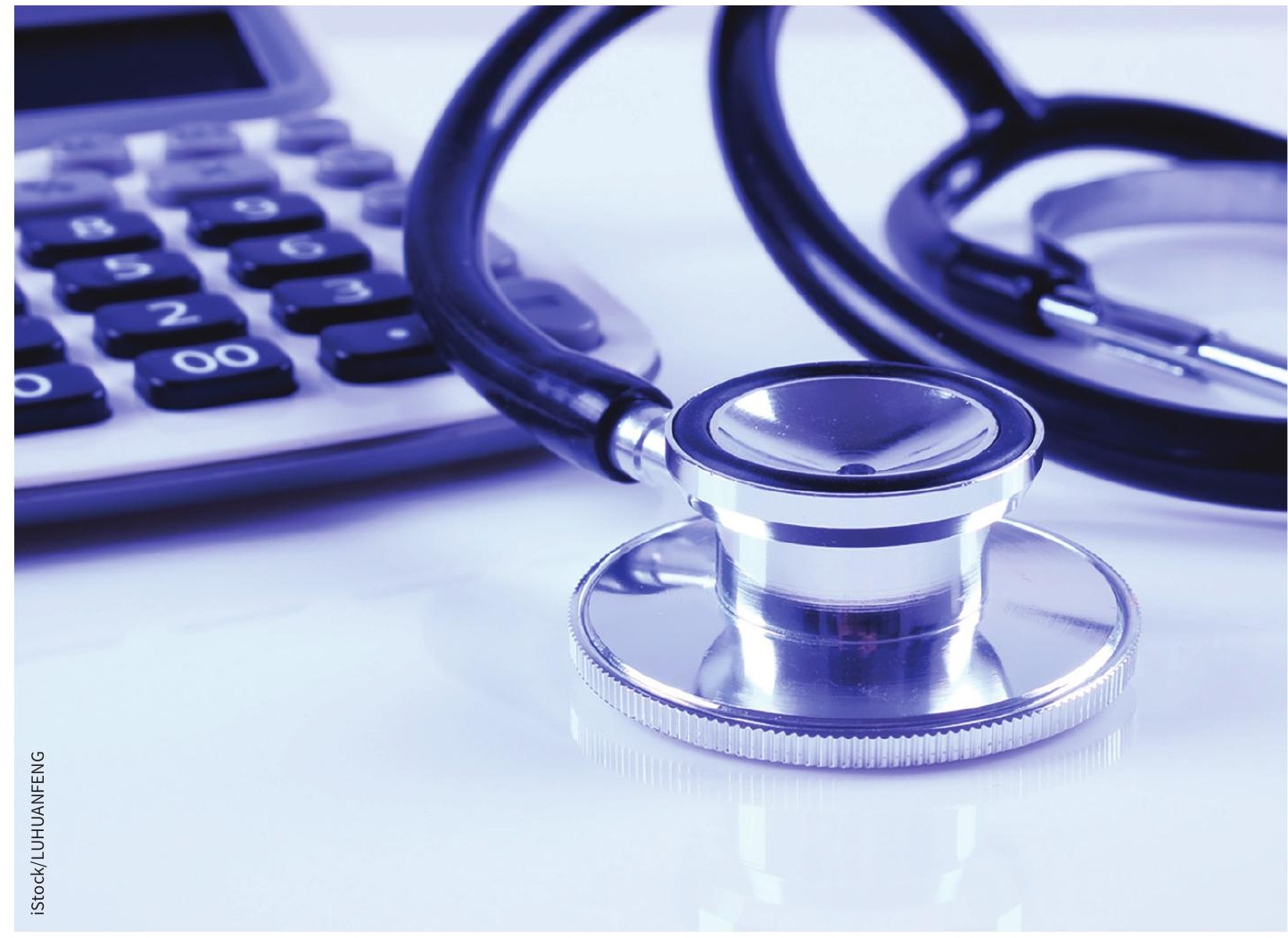

How to divide up the health care budget between family physicians and other specialties has been a fraught issue in Ontario.

"There is clearly a public dispute in the profession about whether the OMA is the exclusive representative of physicians in Ontario," the ministry stated in a letter to the arbitration board.

The OMA argued that the government could not walk away legally from binding arbitration, and the government agreed to return to arbitration a few days later. The OMA also disputes the significance of the vote. In a letter to members, OMA leadership pointed out that only 14 of
Ontario's 49 specialist sections took part in the vote, with just eight voting to break away. "We will continue to argue for a good deal for all sections at the arbitration table - this remains our top priority," the letter states.

Dr. James Swan, a cardiologist and member of the OSA board, says the vote was a demonstration of the frustration specialists have had with the OMA over the past few years. "The OMA fails to understand the needs of specialists and 
the patients we serve," he says. "They have not spent enough time and effort on the needs of specialists."

Swan cites the example of the 2015 cancellation of a premium for some specialists that provided extra money for follow-up visits for patients with chronic conditions. Cancelling the premium made it difficult to deliver specialty care outside of a hospital to some patients, such as those suffering heart failure, he says, and it ended up costing the government more money. He feels the OMA did not do enough to defend the premium. "As a group of specialists, we could sit down with the government and show them how to save money," he says.

There is also the fraught issue of relativity, or how to divide up the health care budget between family physicians and other specialists. This has been a source of ongoing disagree- ments within the OMA and was scheduled to be discussed in phase 2 of the arbitration process early next year. "The relativity model is a huge problem for OMA," says Swan. "We have no confidence the outcome would be fair for all doctors."

Medical specialists have independent representation in only two provinces. In British Columbia, specialists have their own association, but it requires joint membership with Doctors of $\mathrm{BC}$, and the organizations work together in negotiations with the government. In Quebec, the FMSQ has been fully independent for more than 50 years - negotiating fees, health care management and allocation of specialists in the province with the government. The group has done well for its members; earlier this year, it concluded a deal that provided annual salary increases of $1.4 \%$ until 2023, ret- roactive to 2015 (although Quebec's new government wants to revisit the deal). In 2007, specialists in Quebec earned less than their colleagues in Ontario. Now they make $\$ 36000$ more per year, on average.

In order for the OSA to negotiate directly with the Ontario government, a change in legislation is required. Currently, only the OMA has the authority to do so. The OSA also wants the government to revoke the law that makes membership in the OMA mandatory for all doctors in the province. There is some indication that the government may be open to these changes. Health minister Christine Elliott has written to the OSA inviting them to meet to "discuss representation issues of importance to OSA members."

Brian Owens, St. Stephen, NB 